\title{
A PRODUÇÃO DO EFEITO SIMBÓLICO DA ESCOLA PÚBLICA NO ACESSO DE ESTUDANTES AO ENSINO SUPERIOR
}

\author{
THE PRODUCTION OF PUBLIC SCHOOL SYMBOLIC EFFECT IN STUDENTS \\ ACCESS TO HIGHER EDUCATION
}

\section{LA PRODUCCIÓN DEL EFECTO SIMBÓLICA DE LAS ESCUELAS PÚBLICAS AL ACCESO DE SUS ESTUDIANTES A LA EDUCACIÓN SUPERIOR}

Carlos Lopes ${ }^{1}$, Jéssica Reis Evangelista ${ }^{2}$

\section{RESUMO}

O artigo aborda tanto a produção quanto os paradoxos do efeito simbólico de instituição pública de ensino médio, quando do acesso dos seus estudantes à universidade pública. A escola pauta a sua ação em exames de seleção para o ensino superior, mesmo com o ensino médio tendo outras finalidades como a preparação para o trabalho e a cidadania. O efeito esperado da escola é o efeito simbólico, derivado do poder simbólico, sendo esse último, nos termos de Bourdieu (2004), um poder de fazer coisas, poder de consagração ou de revelação e que se faz existir para os outros quando é distinguido. A partir da seleção de escola pública do Distrito Federal (DF), que obteve na imprensa a repercussão por ter estudantes que ingressaram na Universidade de Brasília (UnB), foi realizada a análise documental do Projeto Político Pedagógico da Escola, aplicação de questionário junto a 81 (oitenta e um) estudantes do ensino médio e entrevista com a direção da escola. A construção do efeito simbólico dos resultados da escola se dá em meio a paradoxos a exemplo do não envolvimento de todos os professores em preparar os estudantes aos exames de seleção; estruturalmente, em escala macro e micro, confirma a crise do ensino médio brasileiro em busca de rumos. A tendência é de que escolas busquem suas particularidades por distinção social, aprofundando a desigualdade, conservação e hierarquização na rede escolar.

PALAVRAS-CHAVE: Escola. Efeito simbólico. Ensino Médio. Exames. Universidade Pública.

\section{ABSTRACT}

The article addresses both the production and the paradoxes of the symbolic effect of the High School public institution during the access of students to public universities. The school bases its action on selective exams for higher education, even if the High School has other purposes such as preparing students for work and citizenship. The expected effect of the school is the symbolic school effect, derived from the symbolic power, which, in the terms of Bourdieu (2004), is a power to do things, power of acclamation or revelation and that exists for others when distinguished. From the selection of a public school in Distrito Federal (DF), which received in the media the repercussion for having students who entered the University of Brasilia (UnB), a documental analysis of the Political Pedagogical Project of the school, a survey of 81 (eighty-one) High School students and interviews with the school principal were undertaken. The construction of the symbolic effect of the school results occurs in the midst of paradoxes such as the non-involvement of all teachers in the preparation of students for selective exams; structurally, in macro and micro scales, it confirms the crisis of the Brazilian High School in search of direction. The tendency is that schools seek its particularities by social distinction, deepening inequality, conservation and hierarchy in the school system.

\footnotetext{
${ }^{1}$ Doutor em Ciências Sociais (Sociologia) - Pontíficia Universidade Católica de São Paulo (PUC-SP). Professor Associado da Faculdade de Educação da Universidade de Brasília; Professor do PPGE-FE. (UnB) - Brasília, DF. Brasil. E-mail: carloslopes@unb.br

${ }^{2}$ Graduanda em Pedagogia - Faculdade de Educação da Universidade de Brasília (UnB) - Brasília, DF. Brasil..

E-mail: jessica.reeys@gmail.com
}

Submetido em: 29/10/2016 - Aprovado em: 12/09/2017

(C) ETD- Educação Temática Digital Campinas, SP $\quad$ v.20 $\quad$ n.1 $\quad$ p. 49-65 jan./mar. 2018


KEYWORDS: School. Symbolic effect. High school. Exams. Public University.

\section{RESUMEN}

El artículo discute tanto la producción como las paradojas del efecto simbólica de las escuelas públicas de secundaria con relación al acceso de sus estudiantes a las Universidades Públicas. La escuela fundamenta su acción en exámenes de ingreso a la Educación Superior, aún cuando los propósitos de la Educación Secundaria están orientados a la preparación para el trabajo y la ciudadanía. El efecto esperado de la escuela, es el efecto de la escuela simbólica, derivado del poder simbólico, este último, en términos de Bourdieu (2004), un poder para hacer las cosas, poder de consagración o de revelación y que surge para los demás cuando es distinguido. Tomando como base el impacto que tuvo en la prensa local la selección de alumnos provenientes de escuelas públicas de Brasília (DF) a la Universidad de Brasilia (UnB), se realizó un análisis documental del Proyecto Político Pedagógico de una Escuela y la aplicación de un cuestionario con la participación de 81 (ochenta y un) estudiantes de secundaria y entrevista con directivos-docentes. La construcción del efecto simbólico de los resultados de la escuela se da en medio de paradojas, como por ejemplo de la no participación de todos los maestros en la preparación de estudiantes para las pruebas. Por otra parte, estructuralmente, en escala macro y micro, confirma la crisis de la escuela secundaria brasileña en busca de dirección. La tendencia es que las escuelas busquen sus particularidades de distinción social, la profundización de la desigualdad, la conservación y clasificación en el sistema escolar.

PALABRAS-CLAVES: Escuela. Efecto simbólico. Enseñanza Media. Exámenes. Universidad pública.

\section{INTRODUÇÃO}

Neste artigo apresentamos e discutimos ações instituídas na escola pública pesquisada no que se refere à preparação dos estudantes para o ingresso em universidade pública federal, no caso, a Universidade de Brasília (UnB), por meio do seu Programa de Avaliação Seriada (PAS) ${ }^{3}$. O PAS tem como objetivo integrar a educação básica e o ensino superior, por meio da inserção de estudantes na Universidade de forma gradual e sistemática. O processo de avalição do estudante se desenvolve ao longo dos três anos do ensino médio ${ }^{4}$.

Os estudantes matriculados na modalidade regular de ensino que são pertencentes a escolas públicas ou privadas podem participar do programa. O PAS é dividido em subprogramas que correspondem a 3 (três) etapas, sendo que cada etapa é realizada no final de cada ano do ensino médio. Para cada série são cobrados conhecimentos específicos relativos aos conhecimentos adquiridos no ano de estudo, além das obras estipuladas em edital, que fazem referência à literatura, teatro, música e arte. A classificação dos alunos é realizada pela soma das médias obtidas durante os três anos e o estudante só pode escolher o curso desejado na última etapa.

\footnotetext{
${ }^{3}$ O Programa de Avaliação Seriada - PAS da UnB foi iniciado em 1995 e completou 20 anos em agosto de 2015. A UnB mantém, além da seleção por meio do PAS, o vestibular tradicional e a nota obtida no Enem.

${ }^{4}$ Quando finalizávamos este artigo, o governo Michel Temer publicou a Medida Provisória 746/16 que tratava da reforma no ensino médio. Portanto, por uma questão temporal, essa reforma não será objeto de tratamento em nosso artigo.
}

(C) ETD-Educação Temática Digital Campinas, SP $\quad$ v.20 $\quad$ n.1 $\quad$ p. 49-65 jan./mar. 2018


O Programa oferece 2.110 vagas por ano e são ofertados 97 cursos presenciais de graduação. $O$ aluno do ensino médio pode ingressar pelo sistema universal ou pelo sistema de cotas para alunos de escolas públicas. O decreto $n^{\circ} 7.824$, de 11 de outubro de 2012, regulamenta a lei $\mathrm{n}^{\circ}$ 12.711, de 29 de agosto de 2012, que trata sobre o ingresso nas universidades federais e nas instituições federais de ensino técnico de nível médio. 0 art. 2o desse documento dispõe que $50 \%$ das vagas em instituições federais devem ser destinadas aos alunos de escolas públicas.

Quando do resultado do PAS-UnB em 2016, diferentes manchetes e chamadas de jornal de Brasília, Portal do Governo do Distrito Federal, sítio eletrônico de Confederação Sindical de Professores, deram ênfase ao sucesso do ingresso de estudantes oriundos da escola pública na UnB. Com variações na ênfase, ora em relação ao número dos ingressantes na universidade pública; ora, a escolas públicas específicas, a saber: "Das 2 mil vagas do PAS, 780 são de estudantes da rede pública" ${ }^{5}$ (CB, 13 jan. 2016); "40,88\% das vagas do PAS em 2016 são de alunos da rede pública" (AB, Portal do Governo do DF, 13 jan. 2016); "Sucesso na rede pública: 54 alunos são aprovados no PAS da UnB" (CB, 12 de jan. 2016) e "Escola dá Exemplo de Superação" 6 . (Campanha Educação Pública, eu apoio!, CNTE, 21 jan. 2016)

Nas reportagens citadas, o que dizem os agentes das direções das escolas públicas em relação ao sucesso do ingresso dos estudantes na UnB? Uma primeira diretora entrevistada diz: "A espinha dorsal da nossa escola é a preparação para provas seletivas, como o Enem, PAS e Sisu, mas o mérito é dos alunos. Muitos moram longe, acordam de madrugada para estar aqui todos os dias. São vitoriosos" (CB, 13 jan. 2016, grifo nosso). A mesma diretora dessa escola pública na Asa Sul, região central de Brasília, diz na reportagem que esperava o bom desempenho dos estudantes por causa da tradição da escola. Uma segunda diretora afirma na reportagem que o papel da escola é aumentar a autoestima dos alunos e reforçar constantemente que entrar na universidade pública é algo possível e ainda:

Os alunos da escola pública costumam acreditar que não têm potencial, mas, quando um contato dos estudantes com a universidade se desenvolve minimamente, eles se sentem mais seguros. (CB, 13 jan. 2016, grifo nosso)

Fora do "Plano Piloto", área central de Brasília, destaca-se a reportagem que tratou do "sucesso" de escola pública da cidade de Ceilândia-DF. Na reportagem aparece o depoimento do coordenador pedagógico da escola, que afirma que o desempenho é uma conquista para o colégio, conhecido na região pelas aprovações na universidade e que

\footnotetext{
${ }^{5}$ Logo abaixo da chamada vinha a manchete "A Conquista na Rede Pública" (CB, 13 jan. 2016).

${ }^{6}$ Matéria replicada do Jornal Correio Braziliense do dia 16 de janeiro de 2016.
}

(C) ETD- Educação Temática Digital Campinas, SP $\quad$ v.20 $\quad$ n.1 $\quad$ p. 49-65 jan./mar. 2018


"Todo o nosso trabalho pedagógico para o ensino médio é voltado para as avaliações nas obras do PAS" (Campanha Educação Pública, eu apoio!, CNTE, 21 jan. 2016, grifo nosso).

Diante desse contexto, movemo-nos, assumindo os termos de Berger (1986, p. 2829), pela curiosidade de compreender "as vozes por trás da porta fechada" de dado fenômeno, desejando abri-la. Berger e Luckman (2008) afirmam que a realidade subjetiva é sempre dependente das estruturas específicas de plausibilidade, dependendo da base específica e dos processos que sua manutenção demanda. Nessa busca compreensiva do fenômeno, pretendemos desvelar e discutir teoricamente a posição social da escola dentro do campo educacional, considerando a pauta que essa assume de preparar os estudantes para os exames de seleção à universidade pública. Essa posição tem relação com um universo social mais amplo, apontando para a perspectiva de reprodução de determinadas práticas ou sua transformação (BOURDIEU, 1989).

Há estudos e pesquisas em Sociologia da Educação que se referem ao tratamento da temática da desigualdade social e escolar, provocando e problematizando a questão da longevidade escolar, casos atípicos de sucesso escolar, trajetórias excepcionais, envolvendo estudantes das classes populares que lograram êxito no acesso à universidade pública e ainda aborda-se a relação família-escola, explicando os processos que possibilitaram aos jovens das classes populares romperem uma escolaridade de curta duração (ZAGO, 2006). Há outra perspectiva de estudo e pesquisa, representada aqui no pensamento de Bourdieu e Passeron (2009), que é aquela que relaciona as desigualdades sociais e educacionais, caracterizando a instituição escolar em sua função conservadora, hierarquizadora, reforçando prestígios sociais os mais diversos, dissimulada pelo discurso meritocrático. Essa perspectiva reforça aquilo que é denominado de excluídos do interior, no sentido de Bourdieu e Champagne (2001), caracterizando-se por práticas dissimuladas de exclusão e que é orientadora da nossa análise.

Pesquisa de Zago, Andrade e Anjos (2002), evidenciam que na correlação origem social, passado escolar de inscritos e aprovados no vestibular da Universidade Federal de Santa Catarina, houve forte desigualdade de acesso ao ensino superior e a seletividade fundada na hierarquia dos cursos universitários. Depreende-se dessa pesquisa que, mesmo que a escola pública reforce perspectivas compensatórias de preparação dos estudantes para ingresso na universidade pública, a desigualdade tende a se manter em função da hierarquia social dos cursos, que tendem a privilegiar os privilegiados econômica e culturalmente em relação ao sucesso na aprovação em cursos denominados de elite (os mais concorridos, por exemplo). Portanto, no contexto de expansão do acesso ao ensino superior público "não há uma relação linear entre a ampliação do acesso e a redução da iniquidade no sistema" (PRATES; COLLARES, 2014, p. 105). O estudo apresentado por Borges e Carnielli (2005) evidencia que o Programa de Avaliação Seriada (PAS), da Universidade de Brasília (UnB), em relação ao ingresso de estudantes em cursos de maior prestígio social

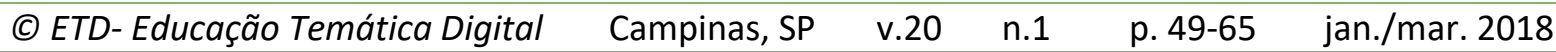


(Medicina, Direito e Engenharia Civil) não se diferencia do vestibular tradicional, tornandose uma nova via para reforçar a estratificação social na universidade, visto que, os alunos selecionados para estes cursos são oriundos de estratos socioeconômicos mais altos, provenientes de instituições particulares, de famílias com maior escolarização e que usufruíram de uma significativa formação educacional. Conclui-se, também, que ambos os processos de seleção (PAS e vestibular tradicional) possuem uma concepção meritocrática. Cesar (2013) corrobora a pesquisa de Borges e Carnielli (2005), mostrando que o PAS (UnB) não se diferencia significativamente do vestibular em relação ao perfil socioeconômico dos estudantes selecionados. Isto é, o programa é uma variedade aparente de acesso à educação superior e que dentro da universidade pública existe uma estratificação interna, conforme a seletividade dos cursos. Afirma ainda que a expansão de vagas na educação superior não diminui os efeitos da estratificação no acesso, sendo necessária a implementação de estratégias para minimizar as desigualdades educacionais, sociais, econômicas e culturais. Prestes, Jezine e Scocuglia (2012), discorrendo sobre a democratização do Ensino Superior Brasileiro, o caso da Universidade Federal da Paraíba, argumentam que as diferenças de classe também são reproduzidas nos processos de acesso aos conhecimentos produzidos nas universidades públicas e em instituições de pesquisa. Reforça que o processo de democratização desse nível de ensino não é suficiente para romper com o caráter elitista da universidade, sendo indispensáveis ações voltadas para a permanência do estudante na instituição, assim como a oferta do ensino de qualidade.

\section{ENTRANDO EM CAMPO: A REALIZAÇÃO DA PESQUISA}

Para viabilizarmos a pesquisa, selecionamos uma escola pública do Distrito Federal que atendesse aos seguintes critérios: tenha sido escola citada em matéria jornalística como tendo bom desempenho dos seus alunos na seleção do PAS-UnB, que a escola não fosse da região central de Brasília (Plano Piloto) ${ }^{7}$ e que houvesse disponibilidade da direção e dos estudantes em participarem da pesquisa. Em visita à primeira escola, identificada em matéria jornalística ${ }^{8}$ e atendendo aos demais critérios estabelecidos, tivemos o aceite na participação na pesquisa e foram assinados os Termos de Consentimento Livre e Esclarecido tanto pela diretora quanto pelos estudantes do 3 o ano do Ensino Médio.

\footnotetext{
${ }^{7}$ Há escolas públicas em Brasília (região do Plano Piloto) que são citadas na mídia como tendo aprovados alunos na UnB. Pensando nisso foi que adotamos o critério de exclusão de Brasília (Plano Piloto) e optamos por outra região administrativa do Distrito Federal.

${ }^{8}$ Cf. Matéria publicada no Jornal Correio Braziliense, em 28/01/2016, sob o título "Pais fazem fila para garantir matrícula", mencionando as escolas públicas campeãs do PAS-UnB. Disponível em:

http://www.correiobraziliense.com.br/app/noticia/euestudante/ensino educacaobasica/2016/01/28/ensino educacaobasica interna,515561/pais-fazem-fila-paragarantir-matricula.shtml. Acesso em: 13 jun. 2016.
}

(C) ETD- Educação Temática Digital Campinas, SP $\quad$ v.20 $\quad$ n.1 $\quad$ p. 49-65 jan./mar. 2018


Fizemos conexão entre o caso selecionado e as matérias jornalísticas que citaram escolas que tiveram bom desempenho no PAS, ampliando nossa reflexão a partir de variações ou contingências do fenômeno. Dessa forma, trabalhamos as fronteiras do fenômeno (MILES; HUBERMAN, 1994) presentes em outras escolas públicas que tiveram bom desempenho no PAS, mas sem intenção de compará-las.

\section{DADOS DA REGIÃO, DOS ESTUDANTES E DA ESCOLA}

A escola onde houve a pesquisa fica em cidade do Distrito Federal que abrigou população que contribuiu para a construção de Brasília, distante $30 \mathrm{~km}$ do centro da capital. A população da cidade tem mais de cento e quarenta mil habitantes e a renda salarial média é de cinco salários mínimos e meio. A escola foi a primeira da cidade a oferecer o ensino médio e ainda tem oferta do curso de Educação de Jovens e Adultos. A cidade tem um shopping center, biblioteca pública, estádio de futebol e campus da UnB. O abastecimento de água na cidade chega a 95,29\% das residências; o serviço de limpeza urbana a 95,29\% e a rede de esgoto atende $91,09 \%$ e todos contam com o fornecimento de energia elétrica.

Em 2014, a escola realizou um levantamento do perfil dos alunos da instituição ${ }^{9}$. $62 \%$ dos matriculados na escola é oriundo da cidade; $27 \%$ são de cidades do estado de Goiás e $11 \%$ de outras regiões do Distrito Federal. Em relação à renda familiar mensal dos pais dos alunos, há o seguinte quadro: até um salário mínimo (9\%), de 1 a 3 salários mínimos (41\%), de 3 a 6 salários mínimos (25\%), de 6 a 9 salários mínimos (16\%) e de 9 a 12 salários mínimos (8\%). Quanto ao grau de escolaridade do responsável, os dados são: fundamental incompleto (13\%), fundamental completo (5\%), ensino médio incompleto (16\%), ensino médio completo. (32\%), superior incompleto (7\%), superior completo (18\%) e pósgraduação (9\%). Já em relação aos hábitos de estudo dos alunos, do total de entrevistados, apenas $15 \%$ deles disseram usar a internet para pesquisa escolar e quando o assunto é tempo disponível para estudar, $22 \%$ afirmam não ter nenhum tempo. No Projeto Pedagógico da Escola é apontado que $94 \%$ dos estudantes pretendem fazer PAS/UnB ou o Enem/MEC.

A escola apresenta uma ótima estrutura, possuindo trinta salas de aula, teleclasse, sala de professor e de coordenação pedagógica, sala de mecanografia, laboratórios de informática, física e química, sala de recursos para alunos com deficiência auditiva, biblioteca, auditório, sala de ginástica, sala para o grêmio estudantil, quatro quadras poliesportivas com dois vestiários, pátio coberto, estacionamento, entre outros.

\footnotetext{
${ }^{9}$ Foram aplicados e respondidos 1.506 questionários de um total de 1.805 questionários aplicados junto às turmas regulares do ensino médio (informação extraída do Projeto Político Pedagógico da Escola).

(C) ETD-Educação Temática Digital Campinas, SP $\quad$ v.20 $\quad$ n.1 $\quad$ p. 49-65 jan./mar. 2018
}




\section{PARADOXOS NO ACESSO À UNIVERSIDADE PÚBLICA}

Em entrevista com a diretora, quando perguntada sobre a finalidade do ensino médio no Brasil, essa respondeu que na Lei de Diretrizes e Bases da Educação, Projeto Político Pedagógico da Escola e Secretaria da Educação do DF, destacam-se três aspectos da formação nesse nível de ensino: a formação para a cidadania, preparação para o trabalho e a continuidade dos estudos. E arremata: "Então eu acho que são muitos objetivos e a gente não foca em nenhum. A escola tem que focar. Nossa escola foca mais no PAS, mas eu acho que não deveria ser assim não". (DIRETORA, ENTREVISTA, grifo nosso)

A entrevistada corrobora a Lei de Diretrizes e Bases da Educação Nacional (LDB) no 9394/96, que estabelece como finalidades para esse nível de ensino: "I - a consolidação e o aprofundamento dos conhecimentos adquiridos no ensino fundamental, possibilitando o prosseguimento de estudos; II - a preparação básica para o trabalho e a cidadania do educando, para continuar aprendendo, de modo a ser capaz de se adaptar com flexibilidade a novas condições de ocupação ou aperfeiçoamento posteriores".

No questionário específico aplicado por nós para essa pesquisa, a 81 estudantes de três turmas do terceiro ano do ensino médio, tivemos alguns dos seguintes resultados: $82 \%$ pretendem ingressar na universidade pública; $13 \%$ responderam ingressar no ensino superior privado; $2 \%$ arrumar um emprego; $2 \%$ pretendem abrir o próprio negócio e $1 \%$ disse não ter expectativas. Somados, o percentual da expectativa de ingresso no ensino superior público e privado alcançam o patamar dos 95\%. A percepção dos estudantes quanto às expectativas das suas famílias em relação ao acesso ao ensino superior também está alinhada ao dado acima, pois corresponde a $84 \%$ em relação ao ingresso no ensino superior público e $10 \%$ no ensino superior privado, que somados totalizam $94 \%$.

Outro dado identificado na pesquisa foi que $74 \%$ dos respondentes disseram que tanto foram informados quanto incentivados pela escola em participarem do PAS-UnB. Todavia, os estudantes não indicam o PAS-UnB como a melhor forma de ingresso na UnB e sim o Enem, representado por $64 \%$ dos respondentes.

O conceito de escola presente no discurso da diretora tem relativa proximidade com o denominado efeito da escola ${ }^{10}$. Efeito escola entendido na relação entre processo e produto, tornando-se tangível em medidas objetivas: alunos aprovados no processo de seleção à universidade pública. Quando dissemos da relativa proximidade com o efeito

\footnotetext{
${ }^{10}$ Não é nosso objetivo apresentar elementos de causa e efeito em relação ao efeito escola no desempenho dos alunos enquanto expectativas ou atitudes que Ihes possibilitariam ingressar no ensino superior público, mas sinalizar para dado evidenciado na pesquisa enquanto tendência geral da escola. Pesquisa quantitativa ou qualiquanti podem ser realizadas nessa direção, a exemplo da investigação que tem o título "A Pesquisa sobre o efeito das escolas: contribuições metodológicas para a sociologia da educação" (ALVES; SOARES, 2007).
} 
escola é por que o efeito não é tanto em função do número de estudantes que são aprovados na seleção, mas na dimensão do capital simbólico (BOURDIEU, 2004) de ter aprovados. Trata-se de um efeito simbólico. Então, a escola pauta a sua ação com ênfase nos exames de seleção para o ensino superior, mesmo em um horizonte em que o ensino médio tenha outras finalidades como a preparação básica para o trabalho e a cidadania.

Para consagrar-se simbolicamente, a escola opera um discurso performativo em relação ao acesso dos estudantes à universidade pública, buscando créditos no seu reconhecimento tanto interno quanto externo à comunidade escolar. Isto é, a direção induz e mobiliza o grupo interno de professores em torno da causa que Ihe consagrará poder simbólico pela continuidade dos estudos dos alunos no ensino superior público, independente do significado numérico desse alcance. Assim, o poder simbólico é um poder de fazer coisas, poder de consagração ou de revelação e que se faz existir para os outros quando é distinguido (BOURDIEU, 2004, p. 166-167). O poder de constituir grupo - no caso em análise, grupo de professores que trabalha com foco nos exames de seleção e a performance dos estudantes - configura o poder simbólico de impor às outras mentes uma visão, antiga ou nova, em que o capital simbólico é o crédito obtido; é o poder atribuído àqueles que obtiveram o reconhecimento (BOURDIEU, 2004, p. 166).

O efeito simbólico dos resultados oculta e revela certos elementos paradoxais da dinâmica educacional e pedagógica nas ações desenvolvidas pelo conjunto da escola pública. Todos os professores da escola se implicam no projeto da escola em orientar seus processos de ensino e aprendizagem para que os alunos se preparem para a seleção da UnB? A diretora da escola responde a essa questão dizendo que são poucos os docentes que se envolvem nesse processo, mesmo com a coordenação sendo voltada para tal foco. A direção incentiva o docente para que prepare os estudantes para a seleção da UnB e complementa:

Se o professor acredita naquilo, ele faz; se ele não acredita, não faz! Eu vejo que são poucos [professores] que trabalham com questões voltadas para o PAS, para o Enem. Na escola pública o professor tem autonomia. Existe um lado bom e um lado ruim. Nós oferecemos as ferramentas, mas ele só vai trabalhar lá na sala de aula se ele quiser. Eu percebo que uma parcela não quer, porque ainda são tradicionais (sic). O professor não está preocupado em pegar uma prova do PAS e trabalhar em sala, de olhar o tipo de questão, como é avaliado, por falta de interesse. Muitos não trabalham porque acham que os alunos não querem e que não é interesse do aluno. Porque assim, qual é a maior reclamação que a gente tem na coordenação e em reunião: que o aluno não está interessado em estudar! Eu ouço isso todos os dias. Então assim, você não vai pra sala de aula apenas pra ensinar. Primeiro você tem que motivar. É difícil você motivar quem não quer. Os professores falam assim 'eles não querem nem o básico! Eles têm dificuldade de fazer uma conta! Como vou pegar uma questão que exige muito raciocínio lógico e trabalhar em sala? (DIRETORA, ENTREVISTA, grifos nosso) 
Bem afirma Bourdieu (2004, p. 165) que, na luta pela produção e imposição da visão legítima do mundo social, a autoridade burocrática nunca detém o monopólio absoluto, mesmo quando estabelece suas alianças.

Como frisado anteriormente, o efeito simbólico do resultado não se dá em função da quantidade, mas do fato de ter um ou dois aprovados, em face do perfil do alunado, repercute em indicador "positivo" diante daquilo que é improvável em certas escolas públicas brasileiras: a aprovação do aluno dessa escola no acesso à universidade pública. Todavia, tal indicador não se dá sem paradoxos no interior da escola. Tanto o Projeto Político Pedagógico da Escola quanto a entrevista da diretora deixam implícita a resistência que se dá no interior da instituição em relação à política de gestão da direção enquanto ênfase em preparar os estudantes para a seleção à universidade pública.

O desenvolvimento de ações estratégias de preparação dos estudantes para o acesso à universidade pública, presentes em programas, projetos e atividades, traz em seu bojo um movimento tendencial de assimilação e aproximação a certos traços típicos da escola empresa na atualidade, marcado por valores mercadológicos na prestação de serviços às expectativas do alunado e pais em relação ao acesso ao ensino superior (FERREIRA; SOUSA, 2014). Ferreira e Sousa (2015) afirmam que a escola empresa pretende formar um indivíduo suficientemente competitivo e apto, cujo êxito deverá trazer maior publicidade à escola, despreocupando-se com todo tipo de dever cívico atrelado à comunidade política. Torres e Quaresma (2014, p.1109), frisam que está ocorrendo a reconfiguração das prioridades da escola, "empurrando-as para a valorização cada vez mais assumida dos valores da eficácia, da excelência e da performatividade, deixando na penumbra a sua missão inclusiva e democrática". A dimensão performativa ainda não alcança grau de institucionalização no Projeto Político Pedagógico da Escola, mas indica paradoxos. O paradoxo se encontra no fato de se afirmar no Projeto Político Pedagógico da Escola que esse deve se alinhar ao perfil dos estudantes e aos seus interesses, mas os dados do levantamento realizado junto aos estudantes são apresentados como contraditórios.

No perfil e interesse dos estudantes há o dado de que $51 \%$ dizem que a finalidade do ensino médio é a preparação para o vestibular; $23 \%$ afirmam que é a formação para o mercado de trabalho e $17 \%$ para preparar para concursos públicos (CEM, PROJETO POLÍTICO PEDAGÓGICO DA ESCOLA, 2014). É frisado no texto do Projeto Político Pedagógico da Escola que essa realidade confirma "o equívoco ao se propor como finalidade para o ensino médio ou a preparação para vestibulares ou a preparação para o mercado de trabalho uma vez que os anseios apontados pelos alunos são variados" (grifo nosso). O fato de haver professores da escola que se implicam, e; outros, não, com a preparação dos estudantes aos exames de seleção à universidade pública, não se configura como algo específico em termos de posições diferenciadas e luta interna em uma escola. Esse caso específico se conecta, tal qual formula Aquino (2012), ao debate mais amplo sobre os objetivos políticos e educativos

$\begin{array}{llllll}\text { (c) ETD-Educação Temática Digital } & \text { Campinas, SP } & \text { v.20 } & \text { n.1 } & \text { p. } 49-65 & \text { jan./mar. } 2018\end{array}$


do ensino médio, considerando suas repercussões no desenho curricular em termos dos enfoques propedêuticos e/ou profissionalizante e com a incorporação dos ideais do humanismo e da diversidade (AQUINO, 2012).

A diretora da escola, indagada sobre o que representa os alunos serem aprovados na UnB, responde: "Às vezes a gente está tão desmotivado na sala: 'Pôxa, o aluno não quer nada! Aí, aquele ali passou: 'poxa, valeu a pena meu trabalho. Pelo menos um, dois, ali foram [aprovados]!”. Em 2015, dos 549 alunos matriculados no 3o ano do Ensino Médio, 43 foram aprovados na UnB.

O efeito do número reduzido de estudantes da escola pública aprovado em exame de seleção à universidade pública confirma a ideia extraída de Oliveira (2008), fazendo alusão a Bourdieu, quando diz que a existência de uma trajetória média comum a integrantes de determinada classe social, faz pressupor que aqueles indivíduos que têm pontos de chegada diferentes da maioria são vistos como possuidores de uma trajetória atípica. Assim, continua o autor, o efeito da trajetória individual, enquanto desviante da trajetória coletiva, por ser bastante visível, cumpre a função de ressaltar o efeito da trajetória coletiva (como a exceção que confirma a regra) (OLIVEIRA, 2008). No caso do Brasil

quando um aluno da escola pública consegue ser aprovado no vestibular para estudar em uma universidade pública, sem ter feito cursinho preparatório: ele, a família, o bairro, a escola comemoram. Compartilham a ideia de que, pelo esforço e empenho, é possível romper as barreiras culturais e sociais existentes. De outro lado, este aluno serve de referência para comparação com os demais, que não se 'esforçaram` o suficiente. (GONÇALVES; GONÇALVES, 2010, p. 75-76)

Então, como frisado anteriormente, a aprovação de dois ou três estudantes da escola pública na universidade pública, configura a exceção que confirma a regra! A eficácia simbólica se consagra na exceção.

Das reportagens citadas na introdução deste artigo e da entrevista com a diretora, emergiu o dado de que há a construção de certa imagem simbólica de escola pública como "eficaz" em relação aos estudantes lograrem êxito no acesso ao ensino superior público. 0 fato de a escola ter bons índices de aprovação no PAS-UnB foi a terceira razão apontada pelos estudantes para estudarem na instituição, representando $17 \%$ (CEM, PROJETO POLÍTICO PEDAGÓGICO DA ESCOLA, 2014). ${ }^{11}$

\footnotetext{
${ }^{11}$ A primeira razão para a escolha da escola foi o encaminhamento da escola anterior de Ensino Fundamental ao Centro de Ensino Médio, 33\%; e a segunda razão foi a escolha da família, $29 \%$. A indicação dos colegas, $10 \%$ e proximidades da casa do estudante, $9 \%$; aparecem em últimos lugares.
}

$\begin{array}{llllll}\text { (C) ETD- Educação Temática Digital } & \text { Campinas, SP } & \text { v.20 } & \text { n.1 } & \text { p. } 49-65 & \text { jan./mar. } 2018\end{array}$


A imagem da escola com o foco na seleção para o PAS-UnB é reforçada pela relação associativa que ela tem com cursinho pré-vestibular tradicional de Brasília. A entrevistada afirmou que há dois anos a escola realiza prova simulada do PAS em parceria com cursinho pré-vestibular. Essa iniciativa também fortalece a ação realizada pela Secretaria de Educação do Distrito Federal (SEDF) que, em 2015, pela primeira vez, desenvolveu simulado do Enem, com o intuito de despertar o interesse de professores e alunos para exames de seleção à educação superior, notadamente o Enem e o PAS-UnB ${ }^{12}$. Ainda sobre a iniciativa, o secretário de Educação do Distrito Federal, Júlio Gregório Filho, defende que "A educação pública precisa e está buscando alternativas para oferecer aos estudantes ainda mais condições de competir com aqueles que dispõem de outros recursos para melhorar seus desempenhos nos testes de seleção". Há convergência entre a ação da escola e a iniciativa governamental no âmbito da rede pública em preparação ao PAS-UnB e Enem. A iniciativa da escola a posiciona na rede pública com seu "diferencial" em relação a outras escolas que não dão ênfase na formação enquanto preparação dos estudantes para o PAS-UnB, vestibular ou Enem.

Além de realizar simulados em preparação aos exames de seleção, a escola desenvolve vinte e nove ações pedagógicas (programas, projetos e atividades) dirigidas aos estudantes. Nessas ações há quatro direcionadas ao PAS-UnB com transversalidade em leituras de obras indicadas em preparação a essa seleção. A escola mobiliza os estudantes a pesquisar sobre a realidade da vivência de valores tendo como suporte das obras literárias indicadas pelo PAS; interpretam, contextualizam e dramatizam as obras do PAS utilizando os conhecimentos de diversas áreas; escolhem uma obra do PAS e montam, com a orientação de um professor, o roteiro de filme com base na obra, havendo ainda a realização de um estival de curtas na escola onde são apresentados os filmes produzidos pelos estudantes e avaliados pelos docentes (CEM, PROJETO PEDAGÓGICO DA ESCOLA, 2014 ${ }^{13}$ ).

A direção da escola divulga o PAS e o Enem, oferecendo palestras, passando nas salas, informando como funcionam esses exames de seleção, o que é necessário para a inscrição; diz aos professores para estimularem os alunos; promove reunião com os pais e divulga a lista das obras do PAS, selecionando na biblioteca os livros e deixando mais fácil o acesso para o professor e estudantes (DIRETORA, ENTREVISTA).

\footnotetext{
${ }^{12}$ A iniciativa do simulado preparatório para o Enem faz parte do programa "Por Dentro dos exames do Ensino Médio" (2015) que possui o objetivo de "apresentar informações sobre acesso ao ensino superior e promover reflexões a respeito do mundo do trabalho e vivências de situações de aprendizagem que favoreçam a escolha da profissão de forma consciente". 20 mil alunos da rede pública realizaram o simulado. A prova contou com 180 questões que abordaram as Ciências Humanas e da Natureza, Linguagem, Matemática e Redação (cf. matéria de Pacheco (2016), disponível em: http://www.se.df.gov.br/component/k2/item/3106-sedf-divulgaresultado-de-simulado-para-o-enem.html . Acesso em: 13 ago. 2016.

${ }^{13}$ Fazemos referência ao Centro de Ensino Médio, Projeto Político Pedagógico da Escola, sem citar o nome da instituição. Preservamos assim o anonimato da escola e o da diretora entrevistada.
}

(C) ETD- Educação Temática Digital Campinas, SP $\quad$ v.20 $\quad$ n.1 $\quad$ p. 49-65 jan./mar. 2018


O Serviço de Orientação Educacional - SOE da escola também tem ações direcionadas aos estudantes no campo da informação profissional, tendo como objetivo:

orientar o educando para o exercício de uma profissão coerente com as suas aptidões e interesses adequados à realidade e às oportunidades do mercado de trabalho; [...] divulgar as políticas públicas de acesso ao ensino superior, incentivar, orientar e acompanhar os alunos nos processos de inscrição, para Estágio, ENEM, PROUNI, SISU, FIES, Escolas Técnicas, UNB- PAS/Vestibular, FEPECS. (CEM, PROJETO PEDAGÓGICO DA ESCOLA, 2014)

A direção da escola age como age não por ser algo voluntarioso, mas pelo fato de que a proposta de organização curricular apresentada em seu Projeto Político Pedagógico é explícita em termos de se alinhar às demandas identificadas no perfil dos seus alunos (CEM, PROJETO POLÍTICO PEDAGÓGICO DA ESCOLA, 2014). A incorporação simbólica do foco continuidade dos estudos na universidade pública vai sendo sedimentada na e pela interação entre a direção e grupo de professores que adere a uma concepção de escola performativa de forma consciente ou inconsciente.

A diretora da escola disse em entrevista que, embora o foco da escola seja o PASUnB, isso não deveria se constituir como tal e que "deveria, realmente, ter escola profissionalizante, como opção. [Para] Quem quer ensino médio ou escola profissionalizante" (DIRETORA, ENTREVISTA). Essa visão da diretora nos remete à visão do Durkheim (1975) ao afirmar que a diversidade moral das profissões não deixa de acarretar uma diversidade pedagógica e que cada indivíduo é chamado a preencher na sociedade as funções requeridas de acordo com as suas aptidões particulares e conhecimentos especiais. Dessa forma, interpretando a voz da diretora ao pensamento de Durkheim (1975), numa ordem moral social, o ensino profissionalizante ou a continuidade dos estudos no âmbito da formação acadêmica deveria ter como pressuposto as aptidões dos indivíduos. Essa visão trabalha com a concepção de uma escola neutra em que os estudantes estariam em "pé de igualdade" em relação às situações de estudo e aprendizagem, independentemente do pertencimento à determinada classe social. Os indivíduos são vistos em suas aptidões e interesses, camuflando os conflitos existentes entre grupos e classes sociais e concebendo o desenvolvimento da sociedade de forma harmoniosa.

O fato da diretora da escola pública enfatizar a preparação dos estudantes para o processo seletivo à universidade pública e, concomitantemente, a questão da continuidade dos estudos em cursos técnicos de curta duração, permite-nos concluir que a sua visão é de que as aptidões dos estudantes não estão necessariamente em sintonia com as suas chances sociais de ingresso na universidade. As chances sociais desses estudantes estão diretamente relacionadas às políticas de cota sociais que alcançam as escolas públicas.

A escola levantou dados dos hábitos de estudo dos alunos e foi constatado que apenas $15 \%$ do total de entrevistados disseram usar a internet para pesquisa escolar e, $\begin{array}{llllll}\text { (C) ETD-Educação Temática Digital } & \text { Campinas, SP } & \text { v.20 } & \text { n.1 } & \text { p. } 49-65 & \text { jan./mar. } 2018\end{array}$ 
quando o assunto é tempo disponível para estudar, 22\% afirmaram não dispor de nenhum tempo. Quanto ao dado de que $94 \%$ dos estudantes pretendem fazer exames seletivos, como o PAS/UnB ou o Enem, o Projeto Pedagógico da Escola afirma que "esses dados evidenciam que há uma incoerência entre o objetivo a que os alunos se propõem e o que, de fato, fazem para alcançá-los".

A direção da escola induz a universalização das expectativas de acesso ao ensino superior público, combinando tal discurso com aquele do esforço individual no sucesso em tal projeto. A ida do estudante para cursos técnicos residiria, exatamente, no discurso da aptidão, combinado à justificativa à sua falta de esforço para entrar no ensino superior público. Assim, vai-se fundamentando no sistema educacional a divisão do trabalho, diferenciando o trabalho manual do intelectual; constituindo a visão econômica da educação em que as classes trabalhadoras têm dificuldades, por si próprias, de traçar uma carreira escolar e a profissionalização sendo etapa posterior à educação básica (GUZZO; EUZÉBIO FILHO, 2005; CIAVATTA, RAMOS, 2011).

Quando perguntada sobre qual a expectativa dos alunos ao término do ensino médio e diante das alternativas de arrumar um emprego, fazer um concurso público, entrar na universidade pública (UnB), abrir o próprio negócio, entrar no ensino privado; a diretora respondeu que a escola havia feito uma pesquisa sobre o assunto e que não lembrava bem dos dados, mas tinha a percepção de que uma parte dos estudantes quer cursar uma faculdade, mas que a grande maioria quer mesmo é arrumar um emprego ou até mesmo um estágio.

\section{CONSIDERAÇÕES FINAIS}

O que ocorre numa microestrutura, sustentado em relações sociais mais próximas, no caso em uma escola, repercute ou reforça a estrutura geral, no poder que essa tem de fixar padrões esperados de comportamento ou é induzida do geral para o mais específico no que se refere aos rituais de distinção social numa cultura marcadamente performativa.

Agentes educativos em escolas públicas brasileira de ensino médio têm se mobilizado, em um esforço voluntarioso, para produzir simbolicamente, efeitos diferenciais positivos da sua moralidade como escola de prestígio. Assim, o efeito simbólico de se constituir como escola pública de prestígio representa moeda cultural valorizada diante da comunidade escolar - àquela praticada por outras escolas públicas -, aproximando-se da moralidade das escolas empresa, no que se refere à perspectiva performativa do ingresso efetivo dos estudantes na universidade pública.

A perspectiva do efeito simbólico da escola pública em escala micro, enquanto chances sociais dos seus estudantes ingressarem no ensino superior público, é apenas uma das faces do debate sobre o ensino médio brasileiro. Portanto, a ampliação das vagas em

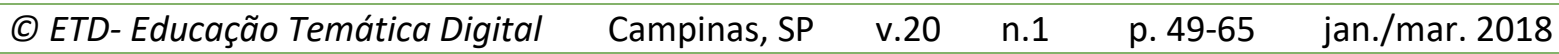


IES públicas para as escolas públicas; "treinamento" em massa para o Enem, em aulas presenciais em ginásios e "online"; cursinhos populares apoiados por governos; simulados para testes específicos de seleção à universidade pública (exemplo do PAS-UnB); parcerias de escolas públicas com cursinhos pré-vestibulares, são elementos do contexto que repercutem e que dão configuração à ação de determinadas escolas públicas em busca de visibilidade pública, consequência do seu poder de fazer coisas. Esse poder de fazer coisas ocorre, paradoxalmente, diante de visões conflitantes sobre as finalidades da escola no ensino médio e de práticas docentes que se inserem ou não em projetos de preparação dos estudantes aos exames de seleção à universidade pública.

No plano macro, na rede pública, uma tendência é a fragmentação excludente das escolas - ênfase de determinadas escolas em exames de seleção ao ensino superior ou formação para o trabalho ou para a cidadania -, na busca por distinção específica entre elas, aprofundando a desigualdade, conservação e hierarquização na rede escolar. A visão do "isso" ou "aquilo" obstaculiza a visão integral da formação no ensino médio, pois reduz a concepção do ensinar e aprender, concentrados em exames e seus simples efeitos simbólicos, por exemplo. O debate público dessa e de outras tendências, a construção coletiva e democrática de proposições no âmbito das unidades escolares, na rede, no sistema e envolvendo outros agentes sociais, representa assumir politicamente que "Algo reconhecido como complexo exige muitas inteligências engajadas, agindo coletivamente". (SOUSA, 2012, p. 566)

\section{'REFERÊNCIAS}

ALVES, Teresa Gonzaga; SOARES, José Francisco. A Pesquisa sobre o efeito das escolas: contribuições metodológicas para a sociologia da educação. Sociedade e Estado, v. 22, n. 22, p. 435-473, maio/ago. 2007.

AQUINO, Orlando Fernández. Apresentação. Ensino em Re-Vista, Uberlândia, MG, v. 19, n.1, jan./jun. 2012. Disponível em:<

http://www.seer.ufu.br/index.php/emrevista/article/viewFile/14897/8397 . Acesso em: 13 ago. 2016.

BERGER, Peter Ludwig. Perspectivas sociológicas: uma visão humanística. 28. ed. Petrópolis, RJ : Vozes, 1986.

BERGER, Peter Ludwig; LUCKMANN, Thomas. A construção social da realidade. Petrópolis, RJ : Vozes, 2008.

BORGES, José Leopoldino das Graças; CARNIELLI, Beatrice Laura. Educação e estratificação social no acesso à universidade pública. Cadernos de Pesquisa (Fundação Carlos Chagas), São Paulo, v. 35, n.124, p. 113-130, 2005.

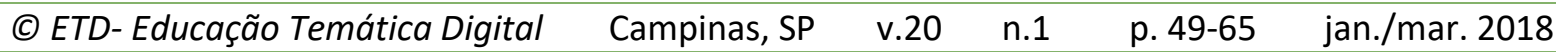


BOURDIEU, Pierre. La noblesse de D’état. Grandes écoles et esprit de corps. Paris : Les Éditions de Minuit, 1989.

BOURDIEU, Pierre. Coisas ditas. São Paulo : Brasiliense, 2004.

BOURDIEU, Pierre; CHAMPAGNE, Patrick. Os excluídos do interior. In: NOGUEIRA, Maria Alice; CATANI, Afrânio (Org.). Escritos de educação. Petrópolis, RJ : Vozes, 2001. p. 217-227.

BOURDIEU, Pierre; PASSERON, Jean-Claude. A reprodução: elementos para uma teoria do sistema de ensino. Petrópolis, RJ : Vozes, 2009.

BRASIL. Lei de Diretrizes e Bases da Educação Nacional. Lei n. 9394, de 20 de dezembro de 1996.

BRASIL. Decreto lei n. 7.824, de 11 de outubro de 2012. Regulamenta a Lei n. 12.7111, de 29 de agosto de 2012, que dispõe sobre o ingresso nas universidades federais e nas instituições federais de ensino técnico de nível médio. Disponível em:

http://www.planalto.gov.br/ccivil 03/ ato2011-2014/2012/Decreto/D7824.htm . Acesso em: 13 ago. 2016.

CEM - CENTRO DE ENSINO MÉDIO DO DF. Projeto pedagógico da escola: educar na diversidade. Triênio 2014-2016. Brasília, DF : CEM, 2014.

CESAR, Layla Jorge Teixeira. Mecanismos de seleção para o ensino superior e desigualdade educacional: um estudo sobre o PAS e o vestibular na Universidade de Brasília. 2013. Dissertação (Mestrado em Sociologia) - Programa de Pós-Graduação em Sociologia da Universidade de Brasília, Brasília, 2013.

DURKHEIM, Émile. Educação e sociologia. São Paulo : Editora Melhoramentos, 1975.

CIAVATTA, Maria; RAMOS, Marise. Ensino Médio e educação profissional no Brasil dualidade e fragmentação. Retratos da Escola, Brasília, v. 5, n. 8, p. 27-41, jan./jun. 2011. Disponível em: http://www.esforce.org.br/index.php/semestral/article/view/45/42 . Acesso em: 13 ago. 2016.

ESCOLA dá exemplo de superação. Campanha Educação Pública, eu apoio. Confederação Nacional dos Trabalhadores em Educação (CNTE), 21 jan. 2016. Disponível em:

http://educacaoeuapoio.com.br/escola-da-exemplo-de-superacao/ Acesso em: 13 ago. 2016.

FERREIRA, Gabriel Lelis da Fonseca; SOUSA, Carlos Alberto Lopes de. O desencantamento moral da escola pública: um ensaio de compreensão crítica. ETD - Educação Temática Digital, Campinas, SP, v. 16, n.2, p. 233-248, ago. 2014. Disponível em: http://periodicos.sbu.unicamp.br/ojs/index.php/etd/article/view/1317/1332 . Acesso em: 13 ago. 2016.

GONÇALVES, Nadia Gaiofatto; GONÇALVES, Sandro Aparecido. Pierre Bourdieu: educação para além da reprodução. Petrópolis, RJ : Vozes, 2010.

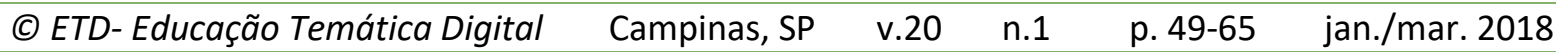


GUZZO, Raquel Souza Lobo; EUZEBIOS FILHO, Antônio. Desigualdade social e sistema educacional brasileiro: a urgência da educação emancipadora. Escritos sobre educação, Ibirité, MG, v. 4, n.2, p. 39-48, dez. 2005. Disponível em:

http://pepsic.bvsalud.org/scielo.php?script=sci arttext\&pid=S1677-98432005000200005 Acesso em: 13 ago. 2016.

MILES, Mattew Bailey; HUBERMAN, Michael. Qualitative data analysis. Thousand Oaks : Sage, 1994.

MOLL, Gabriela; OLIVEIRA, Paulo. 40,88\% das vagas do PAS em 2016 são de alunos. Agência Brasília, Portal do Governo de Brasília, Brasília, 13 jan. 2016. Disponível em:

http://www.agenciabrasilia.df.gov.br/2016/01/13/4088-das-vagas-do-pas-em-2016-sao-dealunos-da-rede-publica/ Acesso em: 13 ago. 2016.

NASCIMENTO, Mariana. A conquista na rede pública. Correio Braziliense, Brasília, 13 jan. 2016. Cidades, Educação, p. 20.

NASCIMENTO, Mariana. Pais fazem fila para garantir matrícula. Correio Braziliense, Brasília, 13 jan. 2016. Cidades, Educação, p. 20. Disponível em:

http://www.correiobraziliense.com.br/app/noticia/eu-

estudante/ensino educacaobasica/2016/01/28/ensino educacaobasica interna,515561/pa is-fazem-fila-para-garantir-matricula.shtml Acesso em: 13 jun. 2016.

NIEDERAUER, Mariana. Sucesso na rede pública. Correio Braziliense, Brasília, 12 jan. 2016. Cidades: política e economia no DF, Educação, p. 19.

OLIVEIRA, Maria Carolina Vasconcelos. Duas formas de pensar os determinantes da prática ou do consumo cultural na sociologia: Pierre Bourdieu e Bernard Lahire. In: IV ENECULT ENCONTRO DE ESTUDOS MULTIDISCIPLINARES EM CULTURA, IV, 2008, Salvador.

Anais...Salvador : Faculdade de Comunicação da UFBA, 2008. Disponível em: http://www.cult.ufba.br/enecult2008/14167.pdf Acesso em: 13 ago. 2016.

PACHECO, Elton. SEDF divulga resultado do simulado preparatório para o Enem. Secretaria de Educação do Distrito Federal, Brasília, 13 jan. 2016. Disponível em:

http://www.se.df.gov.br/component/k2/item/3106-sedf-divulga-resultado-de-simuladopara-o-enem.html . Acesso em: 13 ago. 2016.

PRATES, Antônio A. P.; COLLARES, Ana Cristina Murta. Desigualdade e expansão do ensino superior na sociedade contemporânea: o caso brasileiro do final do século XX ao princípio do século XXI. Belo Horizonte: Fino Traço, 2014.

PRESTES, Emília Maria da Trindade; JEZINE, Edineide; SCOCUGLIA, Afonso Celso.

Democratização do Ensino Superior Brasileiro: o caso da Universidade Federal da

Paraíba. Revista Lusófona de Educação, n. 21, 2012. Disponível em:

http://www.redalyc.org/pdf/349/34924585011.pdf . Acesso em: 13 ago. 2016.

(C) ETD- Educação Temática Digital Campinas, SP $\quad$ v.20 $\quad$ n.1 $\quad$ p. 49-65 jan./mar. 2018


SOUSA, Carlos Alberto Lopes de Sousa. Professor, quero ser oprimida: situação-limite e atoslimites no habitus professoral. Linhas Críticas, Brasília, DF, v. 18, n. 37, p. 551-568, set./dez. 2012.

TORRES, Lima; QUARESMA, Maria Luísa. Configurações da distinção escolar nos planos nacional e internacional. In: MELO, Benedita; DIOGO, Ana Matias; FERREIRA, Manuela;

LOPES, João Teixeira; GOMES, Elias Evangelista Gomes (Org.). Entre crise e euforia: práticas e políticas educativas no Brasil e em Portugal. Porto (Portugal) : Universidade do Porto, 2014. p. 1105-1131. Disponível em:

https://repositorium.sdum.uminho.pt/bitstream/1822/33811/1/Texto\%20\%20EBook\%20Porto.pdf . Acesso em: 13 ago. 2016.

ZAGO, Nadir. Do acesso à permanência no ensino superior: percursos de estudantes universitários de camadas populares. Rev. Bras. Educ., Rio de Janeiro, v. 11, n. 32, p. 226237, maio/ago. 2006. Disponível em:

http://www.scielo.br/scielo.php?script=sci_arttext\&pid=S1413-24782006000200003 Acesso em: 13 ago. 2016.

ZAGO, Nadir; ANJOS; Letícia Merentina dos; ANDRADE, Joelma Marçal de. Seletividade e acesso ao ensino superior público. In: SEMINÁRIO DE PESQUISA EM EDUCAÇAO DA REGIÃOSUL, 4 , 2002, Florianópolis : Universidade Federal de Santa Catarina. Anais... Florianópolis, 2002. Disponível em:

http://www.portalanpedsul.com.br/admin/uploads/2002/Gestao e politicas educacionais/Trabalho/01 0 437 t992.pdf Acesso em: 13 ago. 2016.

\footnotetext{
'Revisão gramatical do texto sob a responsabilidade de: Estela Knitter Barros. E-mail: estelaknitter@gmail.com
} 